\title{
Orthography and Pronunciation in Arabic and English; A Contrastive Analysis
}

\author{
Zikrawahyuni Maiza $^{1}$, Hayati ${ }^{2}$, Arman Husni ${ }^{3}$, Hilma Pami Putri ${ }^{4}$, Rita Febrianta ${ }^{5}$, \\ Eka Rizal ${ }^{6}$ \\ 1,2,3,4,5,6 Faculty of Education and Teacher Training, Institut Agama Islam Negeri (IAIN) Bukittinggi, \\ Indonesia \\ "zikra.wahyuni@iainbukittinggi.ac.id\}
}

\begin{abstract}
Orthography is a part of language study that deals with letter and spelling and a graphic representation of spoken sounds. This paper tries to present a contrastive analysis between orthography and pronunciation of words that contain silent letters in Arabic and English based on script compilations. Based on the circumstance that Arabic and English have their writing system that different from each other, it is found that both of these languages have similarities in the field of silent letters.
\end{abstract}

Keywords: Orthography; Arabic; English; Silent Letters; Contrastive Analysis

\section{Introduction}

Communication is one of the most important things that humans need as social beings. There are more than a trillion pages of information on the Website, most of which are in natural language. The issues that often arise in language processing are pronunciation errors and informal speech. Natural Language Processing (NLP) is a branch of science that focuses on natural language processing. Natural language is the language commonly used by humans in communicating with each other. The development of NLP resulted in the possibility of a natural language interface to a knowledge base and natural language translation. There are several scientific fields related to NLP, namely:

1. Morphology; is knowledge of words and their forms so that they can be distinguished from one another. It can also be defined where a word came from.

2. Phonetics. It is anything related to sound that produces recognizable words. Phonetics is used in the development of NLP, especially in the field of speech-based systems.

This paper will discuss the field of phonetics which is a branch of linguistics. Every language has a different linguistic system such as phonetics/phonology, orthography, morphology, syntax, etc. These differences make it difficult for non-native speaker students to pronounce and read what is written in the language. This situation is also faced by non-native speaker students who learn Arabic and English. Contrastive analysis is expected to help nonnative scholars to be able to conceive both languages easily. As Arabic and English are United Nations language and a well-being utterance is very crucial for communication. This article will talk about a contrast between Arabic language and English language in the area of orthography and pronunciation of words consisting of silent letters for students of Arabic and 
English as a second or foreign language. Silent letters are discussed as part of orthography studies which include letters and spelling. The problem of this study is mispronounced words that have silent letters by non-native speaker students and emerges from the contention that Arabic language and English language share some similarities but differ in some other system. Perhaps, this comparison may help the non-native speaker students to improve the accuracy of their Arabic and English pronunciation, to motivate them in learning both languages, and to encourage the academics to do more papers in the area of morphology, syntax, etc.

Arabic and English are different entirely. Arabic and English have disparate alphabets and vary obviously in standings of complication and the pronouncing system. Arabic is one of the Semitic languages [1]. It is read and written, from right to left. Arabic includes the Modern Standard Arabic (MSA) derived from the Holy Quran. Arabic has 36 letters, it can be classified into 28 basic letters, 6 hamzat letters, ta-marbuta, and alif-maqsura [2]. On the other hand, English is a West Germanic language disclosed to Dutch, Frisian, and German with a compelling amount of vocabulary from French, Latin, Greek, and many other languages. The English alphabet consist of 26 letters. But more than 40 sounds be in place in the English language. From this we understand that the number of letters in a word is not always the same as the number of sounds contained in the word [3]. Meanwhile, Arabic is an inflexional language that contains elaborate morphology with rootlet and form. A rootlet comes out of a set of clear consonants (usually three), which are able to change into an intermittent form to word-formation. Inversely, English is a derived language. That is to approximate, that addition certain affixes enriched the word family not only in terms of writing but also in pronunciation. It caused the effect on scholar's pronunciation. Based on the researcher's observations of students of the Department of Hajj and Umra Management of Bukittinggi Islamic State Institute who learn Arabic and English at the same time, most of them are wrong in pronouncing words that have silent letters.

\section{A. Orthography}

As a part of a language study that deals with letter and spelling, orthography can be defined as a letter composition that conceives a word or a part of the word or it is the process of the word's structure by putting letters together [4]. Nizar mentioned an orthography is a specification of how the sounds of a language are mapped to/from a particular script [5]. It can be concluded that the definition of orthography is the study of procedures for writing and pronouncing letters correctly. The orthography study material is letters and syllables.

\section{B. Pronunciations}

Pronunciation is the foundation of speaking, as it is commonly known. Another explanation of pronunciation is the style or the performance of delivering a sound or a word of a language especially a way that is be understood easily (sound of speech) or simply accepted by the listener. As such, Yates mentioned that pronunciation implies articulating the sounds, practices to deliver the message to the listener or to interact with others. A good communication requires several things, on one section, such as: a deep attention to the sounds of a language (articulation or segmental aspects), a deep attention to aspects of sound structure out the level of basic sounds level (suprasegmental aspects), and to the sound quality. On the other section, pronunciation is measured as the most important part of foreign language study. Yates comments that scholars with proper utterance seem easier to be comprehended even they make mistakes in other areas of the language. Moreover, he elucidates that scholars with meager pronunciation will difficult to be comprehended, although their grammar is perfect [6]. 


\section{Silent Letters}

Silent letters are certain letters that are not enunciated or sounded in a word. Silent letters are discussed in grammar, phonology, and orthography.

\section{Methodology}

This research uses descriptive analysis method with literature study approach

\section{Result and Discussion}

\section{Orthography and Pronunciation of Words Containing Silent Letters in Arabic}

Arabic has comprehensive characteristics recognized by world linguists. Arabic characteristics include phonetic, morphological, syntactic, and rhetorical aspects. The most basic characteristic is the phonetic aspect, in which Arabic has a sound system that is consistent and accurate. The accuracy of the Arabic phonetic sound system is suitable for its semantic context. The consistency of the Arabic phonetic sound system can be seen from the aspect of the silent letter. Some Arabic vocabularies are written but not pronounced, the purpose of giving these symbols as a differentiator with other words that have the same spelling and as an alleviation for articulation (tashêl).

MSA has 34 phonemes (28 consonants, 3 long vowels, and 3 short vowels). The Arabic script has 36 letters and 9 diacritics. Most Arabic letters have a one-to-one mapping to an MSA phoneme [7]. Arabic is a phonetic language. "One letter performs one sound, and 'silent' letters (like 'g' in English 'foreign') and digraphs (like English 'th' 'think' or 'ue' 'argue') do not occur". Nonetheless, there are few omissions. Such omissions could be seen from some of the silent letters in Arabic:

1. $g(w a w)$ is drawn at the end of the word (عمرو) (Amr) although this $و(w a w)$ is unpronounced, we say:

فتح عمرو بن العاص (fataha 'amrobnul 'āsh mishr) (Amr ibn al-āş conquered Egypt). But if the word (عرو) as an object (manşhūb) و is not drawn at the end of the word, we say: أيت عمر (عa-aytu 'amran) (I saw Amr). The word (عمرو) is different from the

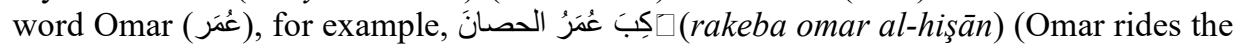
horse). The word Omar is written without $و$ (waw). The function of silent letter $g$ (waw) is to differ between word Amr (عمرو) and Omar (عُرَ).

2. Alif after waw al-jamā'ah is written but is unpronounced, it is written to differ the waw as an original letter of the word or as a sign of plural word. For example: (ar-rejāl الرجال قاّوا (الرجل قام (the men rose up). As for the singular word (ar-rajūl qāma), (the man rose up)

3. $و(w a w)$ in these following words are written but are unpronounced: (أولي) ism isyārah means these, (أولئك) ism isyārah means those, ism isyārah means these.

4. أولو العزمجان الرسل :means owner. Example (أولو) أو (أولى)


سبعمائة

6. Alif-maqşüra, example: عصى (stick) and the word ${ }^{\prime} \square$ (throw). The pattern of silent letters on this word is to alleviate oral speech (tashêl). 
7. The definite article is attached to the beginning of sun letters. The 14 sun letters are:

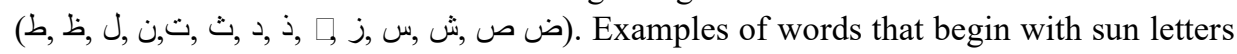

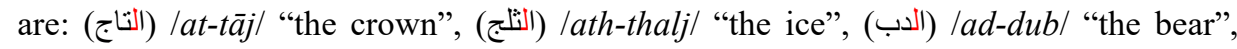

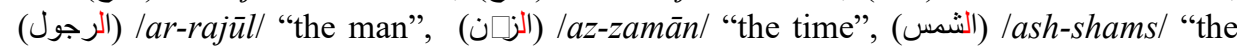
sun", etc. Silent letter $J($ lam $)$ in these words aim to ease the pronunciation (tashêl) because the sun letters are the letters whose pronunciation is near the $J$ (lam) letter. For Arabs, the closeness of letters incriminates pronunciation.

8. Hamzat al-wassl in the middle of the sentence or speech, the connecting hamzat, is an "extra" hamzat at the beginning of the word, pronounced when starting a word, unpronounced when continuing from a previous word or voweled letter. For example: (فاستكبروا) pronounce fastakbarō not fa-istakbarō or fa-astakbarō. Hamzat al-waşl is also written at the beginning of the imperative three-formed word which is preceded by a certain letter and certain nouns from the five-formed and six-formed verbs.

9. Alif tanwēn, for example, كناباً (new book) (kitaaban jadiidan). Silent letter in this pattern as for symbol of tanwèn fathah.

\section{E. Orthography and Pronunciation of Words Containing Silent Letters in English}

English is not phonetic naturally, mostly, the letters in English are not related to its sounds. Carney categorized diverse varieties of silent letters whichever create various grades of impediment [8]:

1. Auxiliary letters: these are created by a group of two letters to epitomize a single phoneme. In this perception they are digraphs.

1.1 exocentric digraphs, where the sound of the digraph produced is diverse from its basic sounds. This category is represented by the "Th for/ $\theta /$, Sh for $/ \int /$ and $\mathrm{Ph}$ for / f /". In the first two illustrations, the phoneme has no average single-letter depiction. In the third example, the standard single-letter depiction uses another character. To exemplify, the "Ph" is used rather than "F".

1.1 endocentric digraphs, where the voice of the digraph is identical as that of one of its basic sounds. These include a) Most doubled consonants, though not duplex consonants as ss in "misspelling". This doubling, which is due to suffixation or alteration, doesn't carry any difficulty for readers. b) The irrelative digraphs whose second element is "e" as in "rate" and "fine". In this type of endocentric digraph, the "e" is silent, and the vowels are elongated. c) Others such as " $\mathrm{Ch}$ " in "check", "Gu" in "guard" and "Ea" in "bread". According to Carney, these sometimes carry impediments for readers.

1.2 Dummy letters which carry no connection to nearby letters and have no coherence in enunciation. These carry certain difficulty for readers, and they are congregated into two categories: 1) Some are sluggish letters, where the letter is articulated in a kindred word, e.g. /n/ in "condemn" and "condemnation", where "n" is silent in "condemn" and articulated in "condemnation". 2) The rest are blank letters which not once have a ring out (sound), e.g. /w/ in "sword", /h/ in "hour" and /b/ in "plumbing". This current huge adversity. They need good phonological alertness to be interpreted correctly. This following table. 1 shows some of the words contain silent letters in English: 
Table 1. The English Words Contain Silent Letters

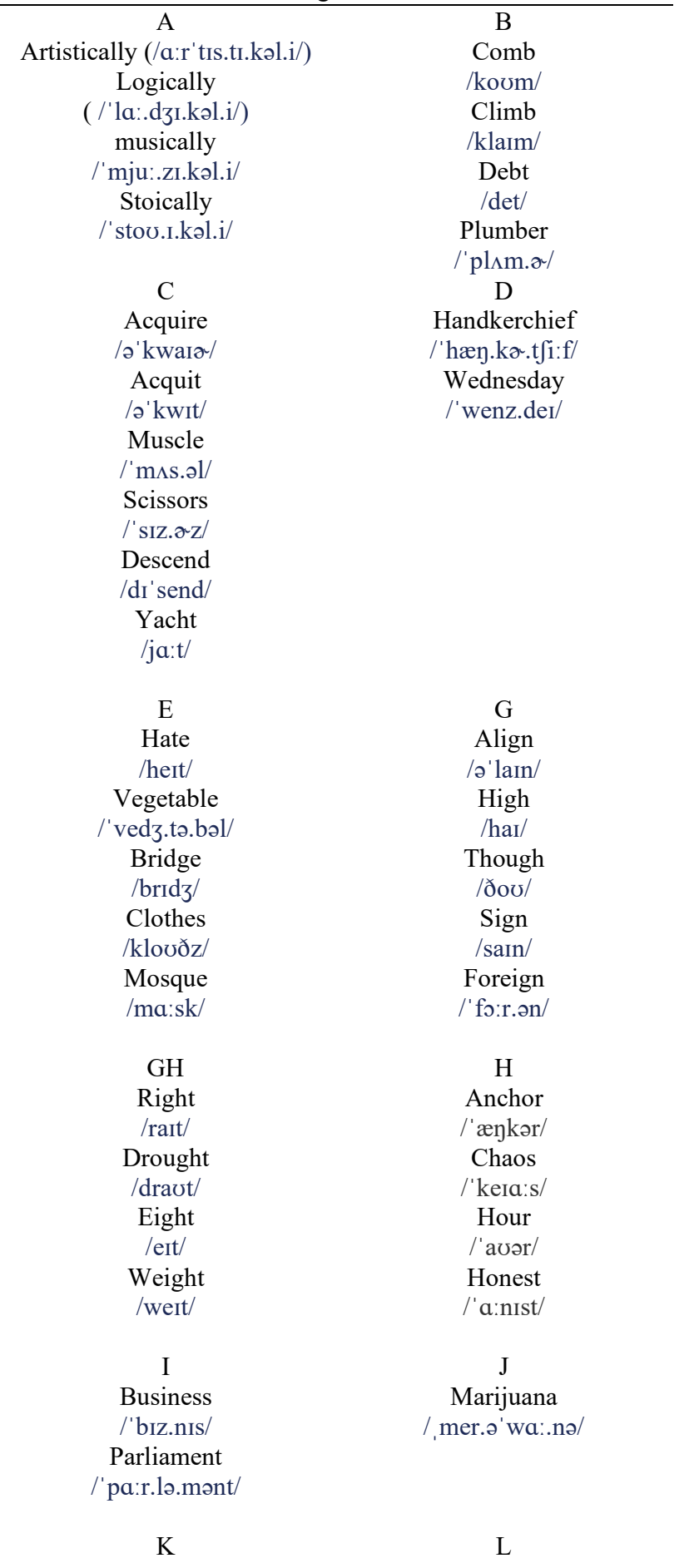




$\begin{array}{cc}\begin{array}{c}\text { Knot } \\ \text { /na:t/ }\end{array} & \text { Calm } \\ \text { Knee } & \text { Folk/ } \\ \text { /ni:/ } & / \text { fouk/ } \\ \text { Knife } & \text { Talk } \\ \text { /naif/ } & \text { /ta:k/ } \\ \text { Knight } & \text { Could } \\ \text { /nait/ } & \text { /kod/ } \\ \text { Knock } & \text { Half } \\ \text { /na:k/ } & \text { /hæf/ } \\ & \end{array}$

Mnemonic

/ni'ma:.nik/

Autumn

/'a.t.təm/

Column

/'ka:.ləm/

Damn

/dæm/

Government

/'guv.ən.mənt/

P

Corps

/ko:r/

Psychology

/sar'ka:.lə.dzi/

Cupboard

/'kıb.əd/

Receipt

/rr'si:t/

\section{S}

Aisle

/arl/

Island

/'ar.lənd/

Viscount

/'var.kaunt/

$\mathrm{TH}$

Asthma

/'æz.mə/

Isthmus

/'is $\theta$.mos/

North

/no:r $r$ /

X

Bordeaux

/bo:r'dou/

Faux

/fou/

$\mathrm{R}$

Butter

/'but.or

Finger

/'frin.ga/

Surprise

/sa'praIz/

$\mathrm{T}$

Listen

/'lis.ən/

Whistle

/'wis.el/

Wrestle

/'res.əl/

W

Whole

/horl/

Wrist

/rist/

Answer

/'æn.sa/

Rendezvous

/'ra:n.der.vu:/ 


\section{Conclusion}

After analyzing the orthography and pronunciation of letters in Arabic and English, the author founds that the silent letters in Arabic phonetics have a pattern (qiyasi) and a few are sima'i. The pattern is consistent and has the aim of facilitating pronunciation (tasheel) and differentiators. In conclusion, there are silent letters in Arabic phonetics which have the purpose of differentiation and tasheel and also some that are sima'i. The phonetic consistency of Arabic is part of the Arabic eloquence. Afterward, the author draws the following significant points:

\begin{tabular}{|c|c|}
\hline Arabic & English \\
\hline $\begin{array}{l}\text { 1. Naturally phonetic language and has flat } \\
\text { orthography. } \\
\text { 2. There is no difference between writing and } \\
\text { pronouncing. } \\
\text { 3. Some words contain silent letters. } \\
\text { 4. The silent letters in the word are easy to } \\
\text { pronounce. } \\
\text { 5. The silent letters in the word are easy to identify. } \\
\text { 6. The purpose of these silent letters as a } \\
\text { differentiator with other words that have the } \\
\text { same spelling. } \\
\text { 7. Most of the silent letters in Arabic have their } \\
\text { pattern (qiyasi). only a few of these words have } \\
\text { no patterns which come from words that are } \\
\text { commonly heard (sima'i) among Arabs. }\end{array}$ & $\begin{array}{l}\text { 1. Naturally not phonetic language and has } \\
\text { deep orthography. } \\
\text { 2. There is a difference between writing and } \\
\text { pronouncing. } \\
\text { 3. Some words that contain silent letters. } \\
\text { 4. The silent letters have difficulty levels to } \\
\text { pronounce. } \\
\text { 5. Difficult to identify which letter that has to } \\
\text { be 'mute' in a word. } \\
\text { 6. Silent letters in English occurs when the } \\
\text { words are borrowed from other languages, } \\
\text { meanwhile, some other words have it to fit } \\
\text { it with the phonological rules in English. }\end{array}$ \\
\hline
\end{tabular}

This article may not be perfect and still requires a lot of advice. Perhaps, it could help the teachers and scholars of Arabic and English when they deal the orthography and pronunciation.

\section{References}

[1] H. M. Ashour, "Major Differences between Arabic and English Pronunciation Systems: A Contrastive Analysis Study", Al-Lisan International Journal For Linguistic\&Literary Studies, vol. 1, Issue. 1, pp. 132-150. 2017

[2] N. Y. Habash, Introduction to Arabic Natural Language Processing, Morgan\&Claypool Publishers: New York, p. 9-11. 2010

[3] H. M. Ashour, "Major Differences between Arabic and English Pronunciation Systems: A Contrastive Analysis Study", AIJLLS, vol. 1, Issue. 1, pp. 132-150. 2017

[4] Q. A. Dhayef et.al, "Orthography and Pronunciation Systems in English and Arabic: A Contrastive Study", Education and Linguistic Research, vol 6, No.1, pp. 1-11. 2020

[5] N. Y. Habash, Introduction to Arabic Natural Language Processing, Morgan\&Claypool Publishers: New York, p. 9-11. 2010

[6] Q. A Dhayef et.al, "Orthography and Pronunciation Systems in English and Arabic: A Contrastive Study", Education and Linguistic Research, vol 6, No.1, pp. 1-11. 2020 
[7] N. Y. Habash, Introduction to Arabic Natural Language Processing, Morgan\&Claypool Publishers: New York, p. 9-11. 2010

[8] E. Carney, A Survey of English Spelling, Routledge: New York, p. 40-42. 1994

[9] M. M. Hamad, "Contrastive Linguistic English Phonology vs. Arabic Phonology", International Journal of Education and Practice, vol. 2, No.4, pp. 96-103. 2014

[10]MD Yeaqub, "Similarities and dissimilarities of English and Arabic Alphabets in Phonetic and Phonology: A comparative Study", Journal Of Teaching Arabic As Foreign Language, Vol. 2, No. 2, pp. 94-105. 2018 